\title{
Pengaruh Jenis dan Kerapatan Gulma terhadap Pertumbuhan dan Produksi Tanaman Jagung (Zea mays L.)
}

\section{Effect of Species and Density of Weeds on The Growth and Production of Maize (Zea Mays L.)}

\author{
Chintya Ayu Alvionita ${ }^{1}$, Herawati Hamim ${ }^{2}$, dan Dad R. J. Sembodo ${ }^{2}$ \\ ${ }^{1}$ Mahasiswa Jurusan Agroteknologi Fakultas Pertanian Universitas Lampung \\ ${ }^{2}$ Dosen Jurusan Agroteknologi Fakultas Pertanian Universitas Lampung \\ Jln. Prof. Dr. Soemantri Brojonegoro No. 1 Bandar Lampung 35145 \\ Email : chintya.alvio@yahoo.com
}

\begin{abstract}
Maize production in each year tends to decrease. One reason is the weeds. Weeds is an important issue because it can compete with the main crop that can reduce crop production. The purpose of this research to determine: (1). The effect of weeds species on the growth and production of maize, (2). The effect of weed density on the growth and production of maize, (3). Interaction between the type and density of weeds in influencing the growth and production of maize. The research was conducted in Natar, South Lampung and Weed Laboratory Faculty of Agriculture, university of Lampung from December 2014 to April 2015. The treatments arranged factorial (3x5) in a strip plot design with three replications. The first factor is the species of weed that are Asystasia gangetica, Rottboelia exaltata, and Cyperus rotundus. The second factor is 5 weed density that are 0, 10, 20, 40, and 80 populations of weeds $/ \mathrm{m}^{2}$. If the assumptions are met, the data is analyzed using ANOVA, followed by Least Significant Difference Test (LSD) 5\%. The result showed that : (1). Species of weeds affects plant shoot dry weight, the weight of maize cobs, and the weight of grain maize but did not affect plant height, number of leaves, plant populations, cob length, cob diameter, and weighs 100 grains. (2). The density of 40 weeds $/ \mathrm{m}^{2}$ affects weight of 100 grains, but the density of 10, 20, and 80 weeds $/ \mathrm{m}^{2}$ did not affect the growth and production of maize. (3). There is no interaction between species and density of weeds in influencing the growth and production of maize.
\end{abstract}

Keyword: maize, weeds, competition

Diterima: 15 Oktober 2015, disetujui 19 Desember 2015

\section{PENDAHULUAN}

Jagung (Zea mays L.) adalah tanaman pangan yang penting di dunia, selain padi dan gandum. Jagung sebagai salah satu tanaman yang memiliki sumber karbohidrat utama (Tim Karya Tani Mandiri, 2010). Menurut Badan Pusat Statistika (2013) produksi jagung di Indonesia pada tahun 2013 sebesar 18,51 juta ton. Produksi ini mengalami penurunan dibandingkan tahun 2012 sebesar 0,88 juta ton, dengan penurunan produksi jagung maka Indonesia masih melakukan import jagung sebesar 3,2 juta ton dari luar negeri. Salah satu penyebab penurunan produksi tanaman adalah gulma. Menurut Sebayang dkk dalam Pujisiswanto dan 

Jurnal Pertanian Terapan

Hidayat (2008) adanya kompetisi antaran tanaman jagung dan gulma mengakibatkan produksi jagung mengalami penurunan sebesar $13-51 \%$.

Kompetisi antara gulma dan tanaman pada sistem produksi tanaman budidaya berhubungan dengan ketersediaan sarana tumbuh yang ada hanya terbatas jumlahnya, seperti air, hara, cahaya, $\mathrm{CO}_{2}$, dan ruang tumbuh . Faktor-faktor yang mempengaruhi tingkat kompetisi adalah jenis gulma, kerapatan gulma, waktu kehadiran gulma, kultur teknis, dan alelokimia (Sembodo, 2010). Menurut Solfiyeni dkk. (2013) persentase penurunan produksi tanaman akibat kehadiran gulma pada setiap jenis tanaman berbeda tergantung pada jenis dan kerapatan gulma.

\section{METODE}

Penelitian ini dilaksanakan di Lahan Penelitian Natar, Lampung Selatan dan Laboratorium Ilmu Gulma, Fakultas Pertanian, Universitas Lampung dari Desember 2014-April 2015. Bahan dan alat yang digunakan benih jagung hibrida Pioneer 27, tiga jenis gulma: Asystasia gangetica, Rottboellia exaltata, dan Cyperus rotundus, meteran, oven, dan timbangan elektrik. Rancangan perlakuan yang digunakan adalah rancangan faktorial (3x5) dengan 3 kali ulangan. Faktor pertama adalah 3 jenis gulma yaitu Asystasia gangetica, Rottboellia exaltata, dan Cyperus rotundus. Faktor kedua adalah 5 taraf kerapatan gulma adalah $0,10,20,40$, dan 80 gulma $/ \mathrm{m}^{2}$. Lahan penelitian seluan $135 \mathrm{~m}^{2}$ diolah dengan cara dibajak, kemudian dibuat 45 petak dengan ukuran petak 1,5 m x $2 \mathrm{~m}$ dengan jarak antar petak 0,5 meter. Benih jagung ditanam secara tugal sebanyak 1 benih perlubang dengan jarak tanam $80 \mathrm{~cm}$ x $20 \mathrm{~cm}$, setelah tanaman jagung berusia 2 minggu setelah tanam (MST) dilakukan penanaman gulma. Pada kerapatan 10, 20, 40, dan $80 \mathrm{gulma} / \mathrm{m}^{2}$ berturut-turut jarak tanam yang digunakan adalah $(25 \times 40) \mathrm{cm},(25 \times 20) \mathrm{cm},(25 \times 10) \mathrm{cm}$, dan $(12,5 \times 10)$ $\mathrm{cm}$. Pemberian pupuk pertama dilakukan pada 10 HST dengan menggunakan pupuk NPK Phonska 300 $\mathrm{kg} / \mathrm{ha}$ dan Urea $100 \mathrm{~kg} / \mathrm{ha}$, kemudian pemupukan kedua dilakukan pada 6 MST dengan dosis Urea $50 \mathrm{~kg} / \mathrm{ha}$ dengan cara ditugal. Pada penelitian ini variabel pengamatan yang digunakan yaitu pertumbuhan gulma antara lain: pengamatan persentase penutupan gulma dan bobot kering gulma. Pengamatan terhadap pertumbuhan tanaman antara lain: tinggi tanaman, jumlah daun, populasi tanaman, bobot kering tajuk, serta bobot kering akar tanaman. Pengamatan terhadap komponen hasil antara lain: bobot tongkol, panjang tongkol, diameter tongkol, bobot jagung pipilan kering, dan bobot 100 butir biji pada kadar air 14\% pada petak panen berukuran 2,25 $\mathrm{m}^{2}$. Kesamaan ragam antarperlakuan diuji dengan Uji Barlett, untuk menguji kemenambahan model uji dengan Uji Tukey. Bila asumsi terpenuhi, data dianalisis ragam, dilanjutkan dengan Uji Beda Nyata Terkecil (BNT) 5\%.

\section{HASIL DAN PEMBAHASAN}

\section{Pertumbuhan Gulma \\ Persentase penutupan gulma}

Pada Tabel 1 jenis gulma tidak mempengaruhi persentase penutupan gulma, namun kerapatan gulma mempengaruhi persentase penutupan gulma. Semakin tinggi kerapatan yang diberikan maka semakin besar persentase penutupan gulma. Terdapat interaksi antara jenis dan kerapatan gulma dalam mempengaruhi persentase penutupan gulma pada 6 MST (Tabel 2). Rottboellia exaltata memiliki persentase penutupan tertinggi dibandingkan dengan Asystasia gangetica dan Cyperus rotundus pada kerapatan 10, 20, dan 40 gulma $/ \mathrm{m}^{2}$. Ketiga jenis gulma tersebut memiliki persentase penutupan yang sama pada kerapatan 80 gulma $/ \mathrm{m}^{2}$. 
Chintya Ayu Alvionita dkk: Pengaruh Jenis dan Kerapatan Gulma terhadap Pertumbuhan dan Produksi...

Pada Tabel 3 jenis gulma mempengaruhi persentase penutupan gulma. Rottboellia exaltata memiliki persentase penutupan tertinggi dibandingkan dengan Asystasia gangetica dan Cyperus rotundus. Kerapatan gulma mempengaruhi persentase penutupan gulma. Menurut Purwono dan Hartono(2008) semakin rapat pertumbuhan gulma maka persaingan yang terjadi antara gulma dan tanaman pokok semakin hebat.

Tabel 1. Pengaruh jenis dan kerapatan gulma terhadap persentase penutupan gulma 3 MST (\%)

\begin{tabular}{lcc}
\hline \multirow{2}{*}{ Perlakuan } & \multicolumn{2}{c}{ Penutupan gulma 3 MST $(\%)$} \\
\cline { 2 - 3 } & Asli & Tansformasi $\sqrt{ }(\sqrt{ }(\sqrt{ }(\mathrm{x}+0,5)))$ \\
\hline Jenis gulma & & $1,34 \mathrm{a}$ \\
Asystasia gangetica & 18,93 & $1,34 \mathrm{a}$ \\
Rottboellia exaltata & 18,80 & $1,34 \mathrm{a}$ \\
Cyperus rotundus & 18,80 & 2,34 \\
\hline BNT $_{0,05}$ & & $0,92 \mathrm{e}$ \\
\hline Kerapatan gulma/m $^{2}$ & & $1,27 \mathrm{~d}$ \\
0 & 0,00 & $1,38 \mathrm{c}$ \\
10 & 6,22 & $1,50 \mathrm{~b}$ \\
20 & 13,00 & $1,63 \mathrm{a}$ \\
40 & 25,00 & 3,03 \\
80 & 50,00 & \\
\hline BNT 0,05 & & $\mathrm{~B}$ \\
\hline
\end{tabular}

Keterangan: Angka yang diikuti oleh huruf yang sama tidak berbeda nyata berdasarkan uji BNT pada taraf $5 \%$.

Tabel 2. Pengaruh jenis dan kerapatan gulma terhadap persentase penutupan gulma 6 MST (\%)

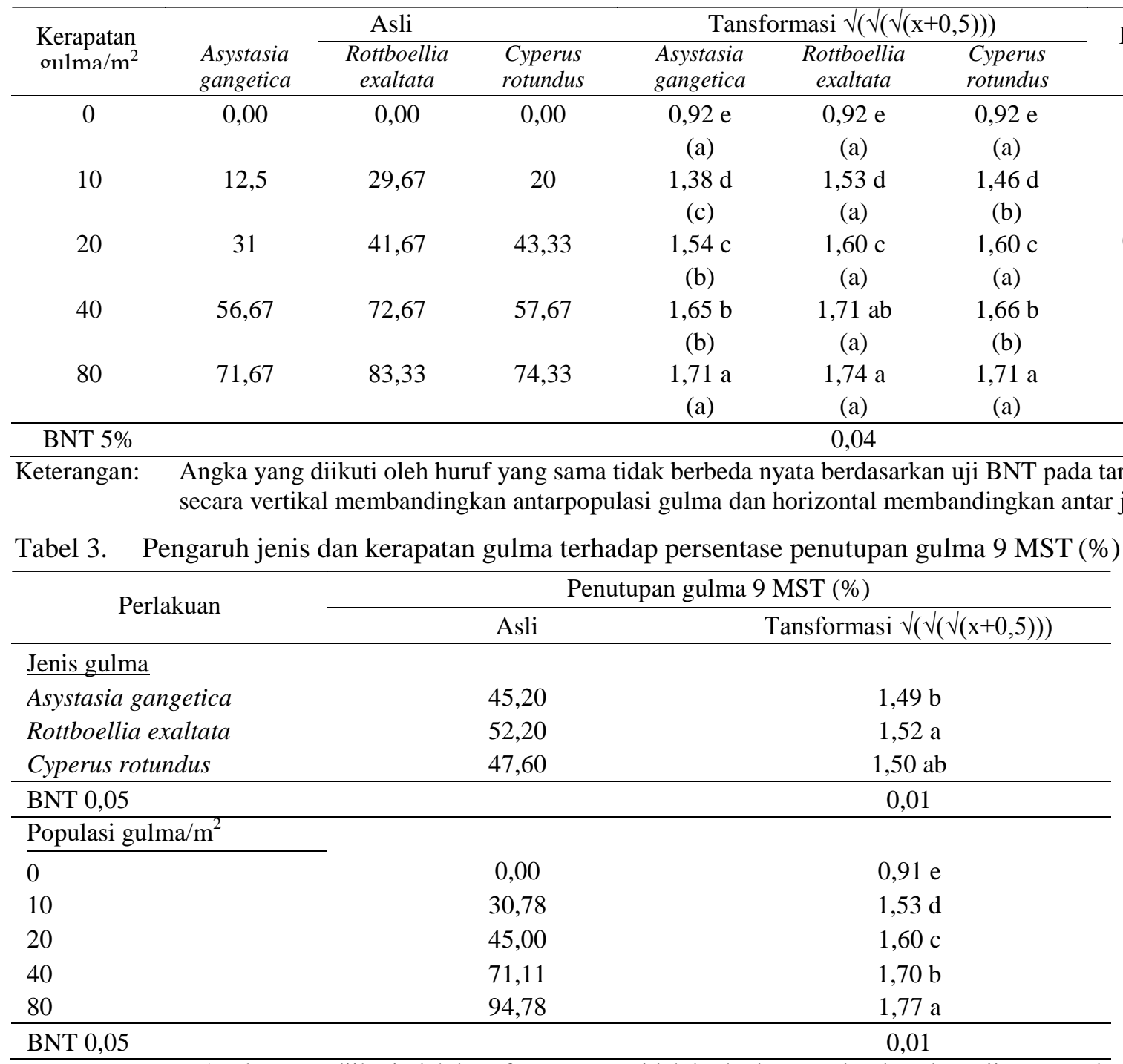

Keterangan: $\quad$ Angka yang diikuti oleh huruf yang sama tidak berbeda nyata berdasarkan uji BNT pada taraf 5\%. 


\section{Jurnal Pertanian Terapan}

\section{Bobot kering gulma}

Terdapat interaksi antara jenis dan kerapatan gulma dalam mempengaruhi bobot kering gulma (Tabel 4). Rottboellia exaltata memiliki bobot kering gulma tertinggi dibandingkan dengan Asystasia gangetica dan Cyperus rotundus pada kerapatan 10, 20, 40 dan $80 \mathrm{gulma} / \mathrm{m}^{2}$. Menurut Arnon (1975) semakin besar bobot suatu gulma maka pertumbuhan gulma semakin baik dan daya saing terhadap tanaman juga semakin baik.

Tabel 4. Pengaruh jenis dan kerapatan gulma terhadap bobot kering gulma $\left(\mathrm{g} / 0,25 \mathrm{~m}^{2}\right)$

\begin{tabular}{|c|c|c|c|c|c|c|c|}
\hline \multirow{2}{*}{$\begin{array}{l}\text { Kerapatan } \\
\text { gulma } / \mathrm{m}^{2}\end{array}$} & \multicolumn{3}{|c|}{ Asli } & \multicolumn{3}{|c|}{ Tansformasi $\sqrt{ }(\sqrt{ }(\sqrt{ }(x+0,5)))$} & \multirow[b]{2}{*}{ BNT 5\% } \\
\hline & $\begin{array}{l}\text { Asystasia } \\
\text { gangetica }\end{array}$ & $\begin{array}{c}\text { Rottboellia } \\
\text { exaltata }\end{array}$ & $\begin{array}{l}\text { Cyperus } \\
\text { rotundus }\end{array}$ & $\begin{array}{l}\text { Asystasia } \\
\text { gangetica }\end{array}$ & $\begin{array}{c}\text { Rottboellia } \\
\text { exaltata }\end{array}$ & $\begin{array}{l}\text { Cyperus } \\
\text { rotundus }\end{array}$ & \\
\hline 0 & 0,00 & 0,00 & 0,00 & $\begin{array}{l}0,92 \mathrm{~d} \\
\text { (a) }\end{array}$ & $\begin{array}{l}0,92 \mathrm{~d} \\
\text { (a) }\end{array}$ & $\begin{array}{l}0,92 \mathrm{~d} \\
\text { (a) }\end{array}$ & \\
\hline 10 & 1,25 & 19,65 & 2,82 & $\begin{array}{l}1,07 \mathrm{c} \\
\text { (b) }\end{array}$ & $\begin{array}{c}1,45 \mathrm{bc} \\
\text { (a) }\end{array}$ & $\begin{array}{c}1,15 \mathrm{ab} \\
\text { (b) }\end{array}$ & \\
\hline 20 & 2,58 & 26,52 & 3,51 & $\begin{array}{l}1,15 \mathrm{~b} \\
\text { (b) }\end{array}$ & $\begin{array}{l}1,50 \mathrm{~b} \\
\text { (a) }\end{array}$ & $\begin{array}{l}1,18 \mathrm{a} \\
\text { (b) }\end{array}$ & 0,08 \\
\hline 40 & 6,84 & 39,82 & 8,73 & $\begin{array}{c}1,28 a b \\
\text { (b) }\end{array}$ & $\begin{array}{c}1,56 a b \\
\text { (a) }\end{array}$ & $\begin{array}{c}1,32 \mathrm{a} \\
\text { (b) }\end{array}$ & \\
\hline 80 & 9,94 & 56,39 & 15,99 & $\begin{array}{c}1,34 \text { a } \\
\text { (b) }\end{array}$ & $\begin{array}{c}1,65 \mathrm{a} \\
\text { (a) }\end{array}$ & $\begin{array}{c}1,41 \mathrm{a} \\
\text { (b) }\end{array}$ & \\
\hline BNT 5\% & & & & & 0,11 & & \\
\hline
\end{tabular}

Keterangan: Angka yang diikuti oleh huruf yang sama tidak berbeda nyata berdasarkan uji BNT pada taraf 5\% secara vertikal untuk membandingkan antarpopulasi gulma dan horizontal untuk membandingkan antar jenis gulma.

\section{Pertumbuhan tanaman}

\section{Tinggi tanaman}

Tabel 5. Pengaruh jenis dan kerapatan gulma terhadap tinggi tanaman jagung pada umur 3, 6, 9 MST.

\begin{tabular}{lccc}
\hline \multirow{2}{*}{ Perlakuan } & \multicolumn{3}{c}{ Tinggi tanaman $(\mathrm{cm})$} \\
\cline { 2 - 4 } & $3 \mathrm{MST}$ & $6 \mathrm{MST}$ & $9 \mathrm{MST}$ \\
\hline Jenis gulma & $65,91 \mathrm{a}$ & $170,31 \mathrm{a}$ & $257,03 \mathrm{a}$ \\
Asystasia gangetica & $67,76 \mathrm{a}$ & $173,64 \mathrm{a}$ & $254,35 \mathrm{a}$ \\
Rottboellia exaltata & $66,38 \mathrm{a}$ & $168,24 \mathrm{a}$ & $251,80 \mathrm{a}$ \\
Cyperus rotundus & 1,85 & 3,87 & 3,41 \\
\hline BNT $_{0,05}$ & & & $251,96 \mathrm{a}$ \\
\hline Kerapatan gulma/m $^{2}$ & $65,05 \mathrm{a}$ & $167,74 \mathrm{a}$ & $256,08 \mathrm{a}$ \\
0 & $67,67 \mathrm{a}$ & $170,26 \mathrm{a}$ & $256,42 \mathrm{a}$ \\
10 & $66,99 \mathrm{a}$ & $173,40 \mathrm{a}$ & $251,96 \mathrm{a}$ \\
20 & $67,32 \mathrm{a}$ & $171,25 \mathrm{a}$ & $254,41 \mathrm{a}$ \\
40 & $66,39 \mathrm{a}$ & $171,00 \mathrm{a}$ & 4,40
\end{tabular}

Keterangan: Angka yang diikuti oleh huruf yang sama tidak berbeda nyata berdasarkan uji BNT pada taraf $5 \%$. 
Chintya Ayu Alvionita dkk: Pengaruh Jenis dan Kerapatan Gulma terhadap Pertumbuhan dan Produksi...

Pada Tabel 5 dapat dilihat bahwa jenis dan kerapatan gulma tidak mempengaruhi tinggi tanaman. Menurut Suwarto dkk. (2005) semakin tinggi dan lebar tajuk jagung akan memberikan penaungan yang semakin besar sehingga gulma akan tertekan pertumbuhannya.

\section{Jumlah daun tanaman jagung}

Pada Tabel 6 dapat dilihat jumlah daun tanaman jagung tidak dipengaruhi jenis dan kerapatan gulma. Menurut Triyono (2010) pertumbuhan daun yang baik mampu menerima cahaya dengan maksimal. Didukung juga dengan pernyataan Pamuji dkk. (2010) penyerapan cahaya yang maksimal mempengaruhi pertumbuhan dan produksi tanaman.

Tabel 6 Pengaruh jenis dan kerapatan gulma terhadap jumlah daun tanaman jagung pada umur 3, 6, dan 9 MST.

\begin{tabular}{|c|c|c|c|c|c|c|}
\hline \multirow{3}{*}{ Perlakuan } & \multicolumn{6}{|c|}{ Jumlah daun (helai) } \\
\hline & \multicolumn{2}{|c|}{$3 \mathrm{MST}$} & \multicolumn{2}{|c|}{$6 \mathrm{MST}$} & \multicolumn{2}{|c|}{ 9 MST } \\
\hline & Asli & $\begin{array}{c}\text { Transformasi } \\
\sqrt{(\sqrt{(}(x+0,5)))}\end{array}$ & Asli & $\begin{array}{c}\text { Transformasi } \\
\sqrt{(\sqrt{(}(\sqrt{x}+0,5)))}\end{array}$ & Asli & $\begin{array}{l}\text { Transformasi } \\
\sqrt{(\sqrt{ }(\sqrt{(x+0,5)}))}\end{array}$ \\
\hline \multicolumn{7}{|l|}{$\underline{\text { Jenis gulma }}$} \\
\hline $\begin{array}{l}\text { Asystasia } \\
\text { gangetica }\end{array}$ & 8,00 & $1,31 \mathrm{a}$ & 11,87 & $1,37 \mathrm{a}$ & 13,27 & $1,38 \mathrm{a}$ \\
\hline $\begin{array}{l}\text { Rottboellia } \\
\text { exaltata }\end{array}$ & 8,06 & $1,31 \mathrm{a}$ & 11,53 & $1,36 \mathrm{a}$ & 12,93 & $1,39 \mathrm{a}$ \\
\hline $\begin{array}{l}\text { Cyperus } \\
\text { rotundus }\end{array}$ & 8,06 & $1,31 \mathrm{a}$ & 11,27 & $1,36 \mathrm{a}$ & 13,67 & $1,39 \mathrm{a}$ \\
\hline $\mathrm{BNT}_{0,05}$ & & 4,67 & & 4,34 & & 4,27 \\
\hline \multicolumn{7}{|l|}{$\frac{\text { Kerapatan }}{\text { gulma } / \mathrm{m}^{2}}$} \\
\hline 0 & 8,00 & $1,31 \mathrm{a}$ & 11,78 & $1,37 \mathrm{a}$ & 13,56 & $1,39 \mathrm{a}$ \\
\hline 10 & 7,78 & $1,30 \mathrm{a}$ & 11,56 & $1,36 \mathrm{a}$ & 13,67 & $1,39 \mathrm{a}$ \\
\hline 20 & 8,22 & $1,31 \mathrm{a}$ & 11,67 & $1,37 \mathrm{a}$ & 13,11 & $1,39 \mathrm{a}$ \\
\hline 40 & 8,11 & $1,31 \mathrm{a}$ & 11,11 & $1,36 \mathrm{a}$ & 13,00 & $1,38 \mathrm{a}$ \\
\hline 80 & 8,11 & $1,31 \mathrm{a}$ & 11,67 & $1,37 \mathrm{a}$ & 13,11 & $1,38 \mathrm{a}$ \\
\hline $\mathrm{BNT}_{0,05}$ & & 6,02 & & 5,61 & & 5,51 \\
\hline
\end{tabular}

Keterangan: Angka yang diikuti oleh huruf yang sama tidak berbeda nyata berdasarkan uji BNT pada taraf 5\%.

\section{Populasi tanaman jagung petak panen}

Berdasarkan pengamatan 3, 6, dan 9 MST populasi tanaman tidak dipengaruhi oleh jenis dan kerapatan gulma. Menurut Pujisiswanto dan Hidayat (2008) populasi maksimum mengakibatkan pertumbuhan gulma tertekan sehingga pertumbuhan dan produksi jagung akan lebih baik.

\section{Bobot kering tanaman jagung}

Pada Tabel 7 dapat dilihat bahwa jenis gulma mempengaruhi bobot kering tajuk tanaman jagung. Bobot kering tajuk tanaman pada perlakuan Rottboellia exaltata lebih tinggi dibandingkan dengan Asysatasia gangetica dan Cyperus rotundus. Jenis gulma tidak mempengaruhi bobot kering akar tanaman jagung (Tabel 8). Kerapatan gulma tidak mempengaruhi bobot kering tajuk dan akar tanman jagung. Penurunan fotosintesis mengakibatkan suplai $\mathrm{CO}_{2}$ untuk fotosintesis berkurang. Akhirnya akan berpengaruh terhadap bobot kering tanaman (Pranasari dkk. 2012). 
Jurnal Pertanian Terapan

Tabel 7. Pengaruh jenis dan kerapatan gulma terhadap bobot kering tajuk tanaman jagung.

\begin{tabular}{lc}
\hline \multicolumn{1}{c}{ Perlakuan } & Bobot kering tajuk tanaman $(\mathrm{g}) / 2$ sampel \\
\hline Jenis gulma & \\
\hline Asystasia gangetica & $215,10 \mathrm{~b}$ \\
Rottboellia exaltata & $239,16 \mathrm{a}$ \\
Cyperus rotundus & $214,48 \mathrm{~b}$ \\
\hline BNT $_{0,05}$ & 9,41 \\
\hline Kerapatan gulma/m $^{2}$ & \\
0 & $226,91 \mathrm{a}$ \\
10 & $219,49 \mathrm{a}$ \\
20 & $209,25 \mathrm{a}$ \\
40 & $226,00 \mathrm{a}$ \\
80 & $232,91 \mathrm{a}$ \\
\hline $\mathrm{BNT}_{0,05}$ & 12,14 \\
\hline $\mathrm{Ke}^{2}$ & \\
\hline
\end{tabular}

Keterangan: Angka yang diikuti oleh huruf yang sama tidak berbeda nyata berdasarkan uji BNT pada taraf 5\%.

Tabel 8. Pengaruh jenis dan kerapatan gulma terhadap bobot kering akar tanaman jagung.

\begin{tabular}{lcc}
\hline \multirow{2}{*}{ Perlakuan } & \multicolumn{2}{c}{ Bobot kering akar tanaman $(\mathrm{g}) / 2$ sampel } \\
\cline { 2 - 3 } & Asli & Tansformasi $\sqrt{ }(\mathrm{x}+0,5)$ \\
\hline Jenis gulma & & \\
Asystasia gangetica & 49,53 & $6,86 \mathrm{a}$ \\
Rottboellia exaltata & 44,13 & $6,64 \mathrm{a}$ \\
Cyperus rotundus & 48,60 & $6,86 \mathrm{a}$ \\
\hline BNT $_{0,05}$ & & 0,60 \\
\hline Kerapatan gulma/m $^{2}$ & & \\
0 & 45,67 & $6,73 \mathrm{a}$ \\
10 & 50,33 & $7,04 \mathrm{a}$ \\
20 & 42,44 & $6,44 \mathrm{a}$ \\
40 & 43,67 & $6,56 \mathrm{a}$ \\
80 & 55,00 & $7,17 \mathrm{a}$ \\
\hline BNT $_{0,05}$ & & 0,78 \\
\hline Keterangan
\end{tabular}

Keterangan: Angka yang diikuti oleh huruf yang sama tidak berbeda nyata berdasarkan uji BNT pada taraf $5 \%$.

\section{Komponen Hasil}

\section{Bobot, panjang, dan diameter tongkol jagung}

Pada Tabel 9 dapat dilihat bahwa jenis gulma mempengaruhi bobot tongkol dan tidak mempengaruhi panjang dan diameter tongkol jagung, sedangkan kerapatan gulma tidak mempengaruhi. Rottboellia exaltata mempengaruhi bobot tongkol jagung. Menurut Paterrson dalam Griffen dkk (2010) gulma Rottboellia exaltata adalah gulma yang mampu beradaptasi dengan lingkungan terbuka dengan sinar matahari yang tinggi, sehingga gulma ini mampu berkompetisi dengan tanaman jagung. Didukung pendapat Pasau dkk. (2008) tajuk tanaman jagung pada umur 9 MST menutupi permukaan tanaman sehingga gulma yang tidak tahan terhadap naungan akan tertekan pertumbuhannya.

Pada Tabel 10 jenis gulma tidak mempengaruhi bobot 100 butir namun kerapatan gulma mempengaruhi bobot 100 butir jagung. Bobot 100 butir jagung pada kerapatan $40 \mathrm{gulma} / \mathrm{m}^{2}$ lebih kecil dibandingan dengan kerapatan lainnya. Hal ini karena pada kerapatan 80 gulma $/ \mathrm{m}^{2}$ gulma terlalu rapat sehingga gulma tersebut bukan hanya berkompetisi dengan tanamandan jenisnya sendiri. Menurut Hasanuddin dkk. (2012) tingkat kerapat yang tinggi menjadikan tanaman bersaing dengan tanaman itu sendiri. 
Chintya Ayu Alvionita dkk: Pengaruh Jenis dan Kerapatan Gulma terhadap Pertumbuhan dan Produksi...

Tabel 9. Pengaruh jenis dan kerapatan gulma terhadap bobot, panjang, dan diameter tongkol jagung.

\begin{tabular}{lccc}
\hline \multicolumn{1}{c}{ Perlakuan } & Bobot tongkol $(\mathrm{kg}) / 2,25 \mathrm{~m}^{2}$ & Panjang tongkol $(\mathrm{cm})$ & Diameter tongkol $(\mathrm{cm})$ \\
\hline Jenis gulma & & & \\
Asystasia gangetica & $3,36 \mathrm{a}$ & $17,60 \mathrm{a}$ & $4,91 \mathrm{a}$ \\
Rottboellia exaltata & $2,76 \mathrm{~b}$ & $17,47 \mathrm{a}$ & $4,89 \mathrm{a}$ \\
Cyperus rotundus & $3,15 \mathrm{a}$ & $17,95 \mathrm{a}$ & $4,93 \mathrm{a}$ \\
\hline BNT $_{0,05}$ & 0,18 & 0,59 & 0,12 \\
\hline Kerapatan gulma/m $^{2}$ & & & \\
0 & $3,11 \mathrm{a}$ & $17,80 \mathrm{a}$ & $5,02 \mathrm{a}$ \\
10 & $3,11 \mathrm{a}$ & $17,88 \mathrm{a}$ & $4,93 \mathrm{a}$ \\
20 & $3,04 \mathrm{a}$ & $17,92 \mathrm{a}$ & $4,73 \mathrm{a}$ \\
40 & $3,16 \mathrm{a}$ & $16,61 \mathrm{a}$ & $4,91 \mathrm{a}$ \\
80 & $3,04 \mathrm{a}$ & $18,14 \mathrm{a}$ & $4,93 \mathrm{a}$ \\
\hline BNT $_{0,05}$ & 0,23 & 0,76 & 0,16 \\
\hline
\end{tabular}

Keterangan: $\quad$ Angka yang diikuti oleh huruf yang sama tidak berbeda nyata berdasarkan uji BNT pada taraf 5\%.

\section{Bobot 100 butir pada kadar air 14\%}

Tabel 10. Pengaruh jenis dan kerapatan gulma terhadap bobot 100 butir.

\begin{tabular}{|c|c|}
\hline Perlakuan & Bobot 100 butir (g) pada KA $14 \%$ \\
\hline \multicolumn{2}{|l|}{ Jenis gulma } \\
\hline Asystasia gangetica & $35,59 \mathrm{a}$ \\
\hline Rottboellia exaltata & $36,20 \mathrm{a}$ \\
\hline Cyperus rotundus & $36,02 \mathrm{a}$ \\
\hline BNT $_{0,05}$ & 1,06 \\
\hline \multicolumn{2}{|l|}{ Kerapatan gulma $/ \mathrm{m}^{2}$} \\
\hline 0 & $36,87 \mathrm{a}$ \\
\hline 10 & $36,50 \mathrm{ab}$ \\
\hline 20 & $36,24 \mathrm{ab}$ \\
\hline 40 & $33,80 \mathrm{~b}$ \\
\hline 80 & $36,25 \mathrm{ab}$ \\
\hline $\mathrm{BNT}_{0,05}$ & 1,37 \\
\hline
\end{tabular}

Keterangan: Angka yang diikuti oleh huruf yang sama tidak berbeda nyata berdasarkan uji BNT pada taraf 5\%.

\section{Bobot pipilan jagung}

Pada Tabel 11 jenis gulma mempengaruhi bobot pipilan jagung, sedangkan kerapatan gulma tidak mempengaruhi bobot pipilan jagung. Bobot pipilan jagung pada perlakuan Rottboellia exaltata memiliki bobot paling rendah dibandingkan dengan perlakuan gulma Asystasia gangetica dan Cyperus rotundus.

Tabel 11. Pengaruh jenis dan kerapatan gulma pterhadap bobot pipilan jagung

\begin{tabular}{lcc}
\hline \multirow{2}{*}{ Perlakuan } & \multicolumn{2}{c}{ Bobot pipilan jagung pada KA $14 \%$} \\
\cline { 2 - 3 } & & Hektar (ton) \\
\hline Jenis gulma & $1,98 \mathrm{a}$ & $8,81 \mathrm{a}$ \\
Asystasia gangetica & $1,68 \mathrm{~b}$ & $7,46 \mathrm{~b}$ \\
Rottboellia exaltata & $1,88 \mathrm{ab}$ & $8,34 \mathrm{ab}$ \\
Cyperus rotundus & 0,12 & 0,52 \\
\hline BNT $_{0,05}$ & & \\
\hline Kerapatan gulma/m $^{2}$ & $1,82 \mathrm{a}$ & $8,09 \mathrm{a}$ \\
0 & $1,88 \mathrm{a}$ & $8,35 \mathrm{a}$ \\
10 & $1,87 \mathrm{a}$ & $8,32 \mathrm{a}$ \\
20 & $1,88 \mathrm{a}$ & $8,34 \mathrm{a}$ \\
40 & $1,78 \mathrm{a}$ & $7,92 \mathrm{a}$ \\
80 & 0,15 & 0,67 \\
\hline BNT $_{0,05}$ & \multicolumn{2}{c}{ Petak } \\
\hline
\end{tabular}

Keterangan: Angka yang diikuti oleh huruf yang sama tidak berbeda nyata berdasarkan uji BNT pada taraf $5 \%$.

12 Volume 16, Nomor 1, Januari 2016 


\section{KESIMPULAN}

Hasil penelitian menunjukkan bahwa (1). Jenis gulma mempengaruhi bobot kering tajuk tanaman, bobot tongkol jagung, dan bobot pipilan jagung namun tidak mempengaruhi tinggi tanaman, jumlah daun, populasi tanaman, panjang tongkol, diameter tongkol, dan bobot 100 butir. (2). Kerapatan $40 \mathrm{gulma} / \mathrm{m}^{2}$ mempengaruhi bobot 100 butir namun kerapatan 10, 20, dan $80 \mathrm{gulm} / \mathrm{m}^{2}$ tidak mempengaruhi pertumbuhan dan produksi tanaman jagung. (3). Tidak terdapat interaksi antara jenis dan kerapatan gulma dalam mempengaruhi pertumbuhan dan produksi tanaman jagung.

\section{DAFTAR PUSTAKA}

Arnon, I. 1975. Mineral Nutrition of Maize Int. Potash.Ints. Worbloufen, Bern Switzerland. Pp. 314.

Badan Pusat Statistik. 2013. Produksi Jagung Indonesia. http://www.bps.go.id/tnmn pgn.php?kat3. Diakses tanggal 16 September 2014.

Griffen, J. L., R. P. Strahan, D. K. Miller, dan K. R. Lejenne. 2010. Tillage Effects on Itcgrass Seedling Emergence and Changes in The Seed Soil Reservoir. J. American Society of Sugar Cane Tecnologists. 30: $81-88$.

Hasanuddin., G. Erida, dan Safmaneli. 2012. Pengaruh Persaingan Gulma Synedrella nodiflora L. GAertn. pada Berbagai Densitas terhadap Pertumbuhan dan Hasil Kedelai. J. Agrista. 16 (3):146-152.

Pamuji, S., dan B. Saleh. 2010. Pengaruh Intensitas Naungan Buatan dan Dosis Pupuk K terhadap Pertumbuhan dan Hasil Jahe Gajah. J. Akta Agrosia. 13 (1): 62-69.

Pasau, P., P. Yudono, dan A. Syukur. 2008. Pergeseran Komposisi Gulma pada Perbedaan Proporsi Populasi Jagung dan Kacang Tanah dalam Tumpangsari pada Regosol Sleman. J. Ilmu Pertanian. 16 (2) : 6078.

Pranasari, R. A., T. Nurhidayat, dan K. I. Pruwani. 2012. Persaingan Tanaman Jagung (Zea mays) dan Rumput Teki (Cyperus rotundus) pada Pengaruh Cekaman Garam ( $\mathrm{NaCl})$. J. Sains dan Seni. 1: 54-57.

Pujisiswanto, H., dan K. F. Hidayat. 2008. Analisis Pertumbuhan Gulma, Tanaman, dan Hasil Jagung dengan Berbagai Kerapatan Kacang Tanah dan Kacang Hijau dalam Sistem Tumpangsari. J. Agrista. 1: 193198.

Purwono dan R. Hartono,. 2008. Bertanam Jagung Unggul. Penebar Swadaya. Jakarta. 66 hlm.

Sembodo, D. R. J. 2010. Gulma dan Pengelolaannya. Graha Ilmu. Yogyakarta. 168 hlm.

Solfiyeni, C., dan R. Muharrami. 2013. Analisis vegetasi gulma pada pertanaman jagung (Zea mays L.) di lahan kering dan lahan awah di Kabupaten Pasaman. Prosiding FMIPA Universitas Lampung. Lampung. $6 \mathrm{hlm}$.

Suwarto., S. Yahya, Handoko, dan M. A. Chozin. 2005. Kompetisi Tanaman Jagung dan Ubikayu dalam Sistem Tumpang Sari. J. Bul. Agron. 33(2) 1-7.

Tim Karya Tani Mandiri. 2010. Pedoman Bertanam Jagung. CV. Nuansa Aulia. Bandung. 208 hlm.

Triyono, K. 2010. Pengaruh dosis glifosat dan jarak tanam terhaap pertumbuhan gulma dan hasil jagung (Zea mays L.). Fakultas Pertanian. Universitas Slamet Riyadi. Surakarta. 